\title{
Female Identity or Power Game? -- Comment on Raziya, Female Sultan of Medieval India
}

\author{
Zehua Chen ${ }^{1}$, Xubiao Yang ${ }^{1}$ \\ ${ }^{1}$ School of History and Culture, Sichuan University, China
}

Keywords: Medieval India; Raziya; Female Identity; Power Game.

\begin{abstract}
Raziya was a female Sultan very rare in Indian history with excellent talent, who made many compelling political achievements in her ruling period. However, due to the long-lasting discrimination \& prejudice to women in a patriarchal society, it was very difficult for her to have wide political support. Raziya's attempts of breaking the restrictions of some traditional views of the Islamic society caused severe dislike of some orthodox Muslims. What was more, Raziya's practice of enhancing monarchy power by restricting the nobles' power damaged the interests of the Turkic nobles taking the absolute majority in the royal court, causing their strong objection \& retaliation, and Raziya's final failure after a short ruling period. The paper discusses whether the main cause of Raziya's failure is her female identity or a power game.
\end{abstract}

\section{Introduction}

Raziya (1205 - 1240) was a famous stateswoman in the Delhi Sultanate Period (1206 - 1526) of India, and a rare female monarch in the Islamic history. During her ruling period (1236 - 1240), the Delhi Sultanate was further consolidated and strengthened in North India; however, due to the loss of the support of Turkic nobles taking the core position in the royal court, Sultan Raziya continuously fell into the traps well-designed by her opponents, and finally captured and killed. The historians give sufficient positive comments and praises, and believe that she is an excellent female sultan with wide political view \& high talents However, in the analysis of the causes of her failure in ruling, [1]the historians have different views and it is difficult for them to draw a final conclusion. Minhaj-ud-din Siraj, a famous historian in the Medieval Ages, said: "Sultan Raziya was a great monarch, who was wise, just and kind, loves her country; she upheld justice, cared for her subjects, and ruled the armies. She was endowed with all of the excellent characters to be a monarch, but it is a pity that as a woman, all of her excellent characters were meaningless in men's view."[2] Many historians in later generations mostly followed the view above and consider that the failure of Raziya was caused by her female identity, and her political failure was destined due to the long-lasting discrimination \& prejudice to women in a patriarchal society. However, some scholars believe that Raziya's political failure was not caused by her female identity but by the power game in the royal court. What is the decisive cause of Raziya's failure after a short ruling period of three years and a half, female identity, power game or other causes? There is neither special study for the important issue in the academia of China, nor deep study relevant abroad, so the paper tries to discuss the issue for inducing some valuable contributions.

\section{Main Political Achievements of Raziya}

Raziya was the most talented monarch of the Delhi Sultanate in the period over 30 years, after Sultan Iltutmish (on the throne during 1211 - 1236) and before Sultan Balban (on the throne during 1266-1286), [3] and she made positive contributions to the consolidation of the Islamic regime of the Medieval India, and the economic \& cultural development of the North India. Her main political achievements include the following aspects: 
Enhancing the centralized feudal monarchy and further facilitating the political unification of North India. Since the ancient time, the Indian Subcontinent had a large number of regimes and was divided in most of time. The political division hindered the overall progress of the countries and the rapid social \& economic development, and was not good for the formation of national consciousness and national consciousness, which is also the reason that a small number of Muslims could rapidly defeat the native Indian armies having absolute advantage in number and establish regime in North India. The Sultan Qutb-ud-din Aibak (on the throne during 1206-1210) established the Delhi Sultanate but died accidentally from falling down from his horse in a polo game in 1210 before establishing an effective state apparatus. [4]His successor Sultan Iltutmish established a series of feudal bureaucracies and operation mechanisms, building a good foundation for the stability \& development of the Islamic regime. Mostly succeeding the thoughts of the former Sultan, Raziya further consolidated the political foundation of the Delhi Sultanate in North India. By enhancing monarchy power and highlighting the authority of the Sultan, she made the state apparatus operate more smoothly and effectively. Meanwhile, she intentionally increased the proportion of non-Turkic nobles in the royal court, and pacified the non-Muslims as the majority of population in the Indian Subcontinent, winning wider political support and making the regime of the Delhi Sultanate a political entity incorporating all hierarchies \& all ethnic groups of North India, instead of a political group of several Turkic elites. In addition, for other religions in the Indian Subcontinent, Raziya adopted relatively tolerant policy and emphasized the peaceful coexistence of religions; the regime secularization practice of Raziya is beneficial for uniting more non-Muslims to consolidate its political foundation, and also beneficial for the long-term stability of the society. The Sultan Raziya's practice of enhancing centralized feudal monarchy was based on the demand of maintaining her own feudal rule \& interests, but also had progressive significance at that time in the historical view.

Adopting flexible and practical diplomacy strategies for temporarily protecting the Delhi Sultanate from the aggression of the Mongolians. Since the Sultan Iltutmish, the Delhi Sultanate was keeping relatively close relationship with some small Islamic regimes around Ghazni in Central Asia, and those Islamic regimes were in the front line of resisting the Mongolian expansion. In 1238, the Mongolian army led by Genghis Khan conquered Khwarazmian regime among them, and the defeated Khwarazmian leader Hasan Qarlugh attempted to establish an overall political \& military alliance, so as to seek political asylum. Raziya welcomed warmly Prince Qarlugh coming for negotiation and granted him the fiscal income of Baran Region. [5]However, as a wise female monarch, and considering the status of the Delhi Sultanate, Raziya did not promise to provide Qarlugh with asylum and to resist the Mongolian army together, but continued implementing a neutral diplomacy strategy, avoiding the attack of the Mongolian army to the Indian Subcontinent. In the historical background at that time, Raziya's decision is undoubtedly wise; facing the Mongolian army several times powerful than her own, Raziya chose to evade temporarily, so in one aspect, the new Delhi Sultanate was not ravaged by the Mongolian army and the North India avoided foreign enemy invasion and great loss of population; in another aspect, the measure bought precious time for enhancing the power of the army and improving the defense capability in the border. In tens of years after the period, the northwest part of the Indian Subcontinent was mainly peaceful and stable.

Funding scholars and intellectuals, and paying attention to the development of culture. As a sciential Muslim woman, Raziya encouraged the education development and paid attention to the inheritance of cultural treasures of India. She established a batch of schools, institutes and public libraries, and encouraged the study of the Quran, the Hadith and the works of some famous philosophers. Besides the classic works of the Islamic world, Raziya also encouraged the study \& inheritance of some essence of the traditional Indian culture; during her rule, all schools had a study climax of Indian works relevant to philosophy, astronomy, literature, etc, and the trend was in fashion for a period particularly in Delhi. [6] 


\section{Main Causes for Raziya's Failure}

Ibn Batutah, a famous Moroccan tourist in the Medieval Ages evaluated Raziya as an "excellent monarch", and Minhaj, a historian, also believed she "has all of the excellent characters to be a monarch"[7]; however, it is a pity that the rule of such an excellent sultan last only three years, six months and six days. The failure of Raziya has complex political and social causes, and some personal causes, which are mainly reflected in the following aspects:

Political causes. The attitude of the Turkic nobles on Raziya's rule was evolved in a process of opposing - supporting - opposing again. In the establishment of the Islamic regime in North India, some Turkic slaves followed their master and fought every dangerous battle with remarkable battle achievements. After the foundation of the Delhi Sultanate, the slaves were promoted to high positions by the Sultan, became feudal nobles and privileged class fast. The nobles' support is the key for a succeeding Sultan to stay on the throne and to ensure the long-term stable regime. Sultan Iltutmish was originally a military leader in Badaun Province but became Sultan chosen by other nobles; for repayment, the Sultan selected 40 nobles whose ancestors were those slaves to form a "Forty-man Group", allowing them to provide suggestions, and to share the benefits from the regime;[8] however, the expanding power of the nobles became the greatest threat to the monarchy power later. At the beginning of the Delhi Sultanate, the Sultan and the ministers relied highly on each other without obvious contrary hierarchies, so the authority of the Sultan was not fully embodied, and the strong power of the nobles could often influence the Sultan's decisions. In the background, the Sultan Iltutmish appointed Raziya, his most talented descendant as the heir, but the Turkic nobles led by the "Forty-man Group" promoted his second son, Rukn-ud-din Firoz as Sultan after the death of Iltutmish. One important reason of the nobles' support to Firoz was that his political talent was plain instead of excellent, so he was easy to be manipulated by the nobles.

Not so long after Firoz came into power, the Turkic nobles turned their support to Raziya, which can be considered as their reluctant action, and the main cause was Shah Turkan, the mother of Firoz. She was originally a slave in the harem, and was often suppressed and bullied by the wives and the concubines of Iltutmish due to her poor origin. After her son came into power, she revenged in a mad way, killed nearly all of former Sultan's wives and concubines once opposing her, and their children. It is said that she once blinded one son of Turkan before killing him because she worried that the son may vie for the throne. [9]In the royal court, Turkan manipulated the affairs of the states and promoted only her relatives, besides of attempting to eliminate officials who might threaten her. Turkan's savage acts drew the fear \& dissatisfaction of the Turkic nobles lead by the "Forty-man Group". Turkan's arrogance \& slaughter finally irritated the nobles and they turned to support Raziya. It is obviously that the nobles' support was just temporary concession which was used by wise Raziya to have the throne by winning the support of the nobles and the people of Delhi quickly.

After coming into power, Raziya's first measure was to enhance the monarchy power, for establishing Sultan's authority and limiting the power of the Turkic nobles. She fully recognized the threat of the "Forty-man Group" for those nobles opposing her at the beginning could not support her for long. Therefore, she boldly appointed non-Turkic nobles including some Hindus to consolidate her political foundation, and some of key positions controlled by Turkic nobles for long were transferred to the non-Turkic nobles. Such measures undoubtedly disappointed the pendulous Turkic nobles, so they betrayed her again after they were aware that the Sultan damaged their vested interests, and jailed Raziya with cabals.

The analysis above shows that the early Delhi Sultanate had an obvious feature that the monarchy power was weak and the nobles had excessive power, which is also one important cause of turbulent political scenes. The support degree of the Turkic nobles determined who could become Sultan and how long a Sultan can stay on the throne in a great extent, and only the persons easy to be controlled by them and capable of protecting their interests were "ideal monarchs" in their mind. Facing the powerful Turkic noble, Raziya with few supporters attempted to weaken them and to strengthen monarchy power, it was obvious that she could hardly succeed, and she paid miserable cost for this. 
Social causes. Raziya's female identity is another important cause for her failure. In the Islamic history, there were seldom women becoming the Sultans of large countries, which was mainly caused by the restrictions \& limits of the Islam to women, women influenced by Islam could seldom contact the outer world, not to mention the politics. Even in the case that some women influenced the politics, their influence was indirect in most of the cases instead of direct intervention, e.g. Shah Turkan as the mother of the Sultan Firoz abovementioned. The restriction of the religion and the long-lasting patriarchal thoughts in the society made women to be in a subordinative position in the Islamic society in the Medieval Ages. After the foundation of the Delhi Sultanate, the Islam and the Hinduism made mutual reference in culture but both of them enhanced the restrictions to the women, which is reflected in the purdah system in a centralized manner. Due to the favor of Sultan Iltutmish, Raziya seldom contacted the harem so she was seldom influenced by the purdah system. She was good at the skills in politics, riding, archery, hunting and military, and had all good characters for a sultan, but her female identity was an important reason of difficulty in obtaining the nobles' support. In the period of the Delhi Sultanate, many of the nobles in the royal court were originated from the Turkic slaves coming to the Indian Subcontinent, and they became arrogant after being promoted to feudal nobles from the soldiers; the long-lasting patriarchal thoughts made the arrogant nobles feel nearly ashamed of being ruled by a woman, so they object to Raziya and her heir to the throne.

After coming into power, Raziya attempted to change the nobles' prejudice to women by some political achievements. Therefore, she had to break the double restrictions from the religion \& society. The core of the purdah system is to isolate women from the outer world with veils or curtains, but Raziya must take off her veil and come to the front stage for effectively controlling the regime and establish her authority as the Sultan. Raziya made every effort to shape herself into the image of a strong man, for this, she did not wear woman clothing, and often showed her face in public in cloak, with a bow and arrows in her hands, and on the back of an elephant, "men could see her face clearly."[10] Raziya's such behaviors breached some inherent traditions of Islamic world so she was blamed and opposed by orthodox Muslims, and suffered from the strong dislike of the Turkic nobles. She tried to prove that a woman can become a competent monarch by being diligent in politics, but her behavior in man's clothes just reflected her helplessness in mind, which can be interpreted as certain concession to the religion and the society; anyway, it was nearly impossible for a woman to change the social prejudice in short time.

In the Medieval India filled with patriarchal thoughts, women inevitably became the vulnerable group of the society, and it was very difficult for them to achieve self-liberation with resistance. The long-lasting discrimination \& prejudice to women in a patriarchal society determined that Raziya's ruling could not be smooth, particularly when there was no strong supporter. Raziya was trying to break the restrictions from the religion and the society, but failed finally.

Personal causes. There are also some personal causes for Raziya's political failure. Lacking ruling experience, being insufficiently mature \& experienced in mind, and the carelessness in handling some important matters are all causes for her losing the support of most of the nobles.

At the beginning of her ruling, Raziya put the enhancement of the monarchy power in the first priority, arranged her trusted followers in important positions, and suppressed the Turkic nobles led by the "Forty-man Group". As abovementioned, the "Forty-man Group" took the absolute core position in the royal court since the period of the Sultan Iltutmish, and could determine the ownership of the regime. The enthronement of Raziya benefited from the temporary concession \& support of the Turkic nobles to a great extent; the suppression to the supporters with wavering stand before the ruling foundation becoming stable could inevitably push them to the other side, the unwise action was precipitate, which might cause the support loss from the people. Also, Raziya promoted Yaqut, a slave from Abyssinia, to stable manager, which caused severe dislike of nobles, since the important position was always held by the Turkic nobles. In addition, the nobles believed that Raziya had dubious relationship with Yaqut because "every time when Raziya got on a horse, she was helped by Yaqut with his arms";[11] in nobles' view, the behavior of Raziya did not meet etiquette, and was too frivolous for them to accept. 
In addition, the marriage between Raziya and Altuniya was also a focus blamed by the nobles. The captured Raziya was imprisoned in Bhartinda Castle, watched by a noble named Altuniya. The historian Minhaj said that Raziya and Altuniya were friends since childhood, and Altuniya loved Raziya for long. [12] The expression can be partially proved by Altuniya's request of marrying Raziya later. After Raziya was captured, Altuniya was abandoned by the nobles of Delhi and he gained nothing good from the regime change, so he decided to change his side. He released Raziya, aiming to the restoration of morale with her influence as Sultan, and to the support from more people; the marriage request from Altuniya to Raziya could be considered that he hoped to gain certain emotional solace from her. When Raziya was in prison, she had to agree with Altuniya's request, and she believed it is the only choice for her to regain the throne. Her carelessness in marriage infuriated her supporters thoroughly, the nobles considered her compromise as pure exchange \& betrayal, so they were disappointed to her; at this point, all nobles as her supporters for long left her, so it was destined that Raziya's effort for regaining the throne would not be successful.

\section{Conclusion}

As a famous female monarch seldom seen in history, Raziya had excellent political achievements in her ruling period; however, due to complex political \& social reasons, and some of her weaknesses, she lost the support of the nobles, and her ruling finally collapsed. Though the female identity of Raziya was an important cause for her failure, the key cause of her failure was the political conflict in the royal court, i.e. the power game among the Sultan, the Turkic nobles and the feudal nobles for protecting their own interests. Facing the Turkic nobles with expanding personal ambitions, Raziya did not want to be controlled by them, so she damaged their interest, causing them to seek a new agent, which is decisive for Raziya's failure. Raziya's ruling had positive aspects, she reorganized the affairs of the state and enhanced the monarchy power, so the political status once disordered after the former Sultan's death was improved, and the country became peaceful and stable, which was positive at that time.

\section{References}

[1] Braham Singh and H.C. Sharma, History of Medieval India, New Delhi: Omega Publications, 2008, p.10.

[2] Abraham Eraly, the Age of Wrath, New Delhi: Penguin Books, 2015, p.76.

[3] Animesh Mullick, Medieval Indian History, New Delhi: Dominant Publishers and Distributors, 2011, p.82.

[4] Animesh Mullick, Medieval Indian History, p.62.

[5] Farhat Jahan, Depiction of women in the sources of the Delhi Sultanate, Aligarh: Aligarh Muslim Unversity, 2012, p.30.

[6] Farhat Jahan, Depiction of women in the sources of the Delhi Sultanate, p.35.

[7] Animesh Mullick, Medieval Indian History, p.80.

[8] Abraham Eraly, the Age of Wrath, p.72.

[9] Iqtidar Husain Siddiqui, Composite Culture under the Sultanate of Delhi, New Delhi: Primus Books, 2012, p.152.

[10]Abraham Eraly, the Age of Wrath, p.75.

[11] R.C. Majumdar, H.C. Rechaudhuri, and Kalikinkar Datta, An Advanced History of India, translated by Zhang Penglin et. al. Beijing: The Commercial Press, the version of 1986, p. 302

[12] Animesh Mullick, Medieval Indian History, p.80. 